\title{
The estimation of temporal and spatial fluctuations in a forest fire hazard index - the case of a forested public area in Japan
}

\author{
K. Tamai \& Y. Goto \\ Forestry \& Forest Products Research Institute, Japan
}

\begin{abstract}
Few studies have estimated the risk of forest fire in individual forest stands using forest data, such as the leaf area index. Mapped estimates of the risk of forest fire would benefit forest management, and could be used to decide restrictions on the public use of forest areas.

In this study, the litter moisture content ratio was predicted with this model and forest fire hazard was estimated in Tatsunokuchi-yama Green Shower Park, with around 40ha forested area for 2 litter drying periods as a trial. This park is located in central Japan. The model was adapted to the area of around 40ha in this park classified into 9 stands with tree height, tree species and slope direction.

The solar radiation on the forest floor and surface soil moisture at $5 \mathrm{~cm}$ depth was recorded in each stand. Precipitation above the canopy was measured with a rain gauge at a weather station in the base area of the Park.

Litter moisture was simulated every 30minutes. Fuel moisture decreased with litter drying speed for each forest stand among simulated days depending on the solar radiation on the each stand floor. Firstly, the simulated result in the defoliate period (24 February-3 May, 2005) is discussed. Litter moisture. was less than $0.2 \mathrm{~g} \mathrm{~g}^{-1}$ and fire risk is judged to be highest in 7 out of the 9 forest stands on 2 May. On the other hand, spatial variation of litter moistue was widest at $0.198-0.811 \mathrm{~g} \mathrm{~g}^{-1}$ on 27 February. This means that the litter drying speed and fire risk is different for each forest stand. Thus, it is significant to construct the forest fire warning system for each forest stand and to manage people's activities in this public forested area to prevent forest fire.
\end{abstract}

Keywords: water budget, solar radiation, forest stand, public forest. 


\section{Introduction}

Historically, the probability of a forest fire occurring has been estimated using time-series weather data. Few studies have estimated the risk of forest fire in individual forest stands using forest data such as the leaf area index (LAI). Mapped estimates of the risk of forest fire would benefit forest management and could be used to determine restrictions on the public use of forest areas.

Fuel drying is thought to be one of the factors that contribute to forest fires; this process is affected by the forest microclimate. Practical early warning systems in use in the USA and Canada estimate the probability of a forest fire occurring using precipitation, air temperature, and relative humidity data to simulate fuel moisture. The litter layer is thin and thought to dry more quickly than other fuels. Because forest fires typically originate in forest litter and then spread upward to stems and canopies, the estimation of the risk of forest fire in individual forest stands requires an understanding of the process of litter drying.

From this perspective, Tamai [1] promoted a model for estimating the litter moisture ratio using data on solar radiation at the forest floor and precipitation. Here, we predicted the litter moisture content ratio and estimated the forest fire hazard using the model of Tamai [1] for Tatsunokuchi-yama Green Shower Park, which has approximately 40 ha of forested area, for two litter drying periods as a trial. The ultimate objective was the construction of a warning system to manage people's activities in this public forested area to prevent forest fire.

\section{Model}

The model for estimating fuel moisture consists of a tank corresponding to the litter layer (Fig. 1). The depth of water in the tank equals the moisture in the litter layer. Precipitation is stored in the tank, and water in excess of the maximum moisture content flows out into deeper soil. The water in the tank decreases with evaporation (E, mm), calculated using Eq. (1).

$$
\begin{aligned}
& E=(a \theta-b) S \quad \text { when } \theta<c \\
& =(a c-b) S \quad \text { when } c \leq \theta
\end{aligned}
$$

where $S$ is the solar radiation on the forest floor $\left(\mathrm{kJ} \mathrm{m}^{-2}\right), \theta$ is the gravimetric litter moisture ratio $\left(\mathrm{g} \mathrm{g}^{-1}\right)$, and $a, b$, and $c$ are parameters in the model. The identified parameters are $a, b, c$, and the maximum gravimetric moisture ratio $\left(\theta_{\max }, \mathrm{g} \mathrm{g}^{-1}\right)$.

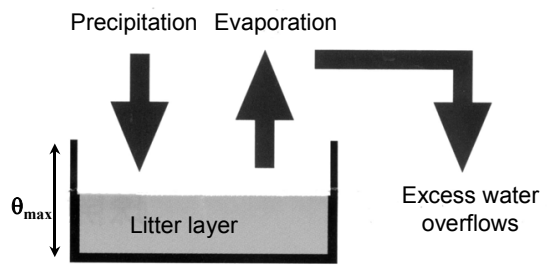

Figure 1: $\quad$ The estimation model for litter moisture ratio. 
Tamai [1] compared the seasonal course of $\theta$ in a mixed deciduous-evergreen forest $\left(35^{\circ} 1^{\prime} \mathrm{N}, 135^{\circ} 46^{\prime} \mathrm{E}\right)$ and in a deciduous forest ( $\left.34^{\circ} 47^{\prime} \mathrm{N}, 135^{\circ} 51^{\prime} \mathrm{E}\right)$ and reported that $\theta$ is smaller and the fire risk higher in deciduous forest than in mixed deciduous-evergreen forest, especially in early spring before deciduous trees are leafing. This suggests that the estimated fire risk depends on forest structure such as radiation penetration to the forest floor.

Moreover, Tamai and Goto [2] fixed the parameters of the model using data measured from two adjacent forest stands. Despite the fact that the parameter values of the two stands were very different, the estimated and measured $\theta$ were not very different. Tamai and Goto [2] concluded that litter moisture depends on the microclimate such as solar radiation, rather than on the intrinsic drying properties of the litter and litter layer.

\section{Site description}

The Tatsunokuchi-yama Green Shower Park is located at $34^{\circ} 42^{\prime}$ N, $133^{\circ} 58^{\prime}$ E. The annual precipitation and mean air temperature are approximately $1200 \mathrm{~mm}$ and $14.3^{\circ} \mathrm{C}$, respectively, and there is no seasonal snow cover. The most dominant species are deciduous trees such as Quercus serrata and Clethra barvinervis. The model was adapted to an approximately 40-ha area in the park classified into six forest types by tree height and species (Fig. 2 and Table 1). No. 1, 4, and 6 forest types were divided into two forest stands each by slope direction. Other forest types were identified as single stands.

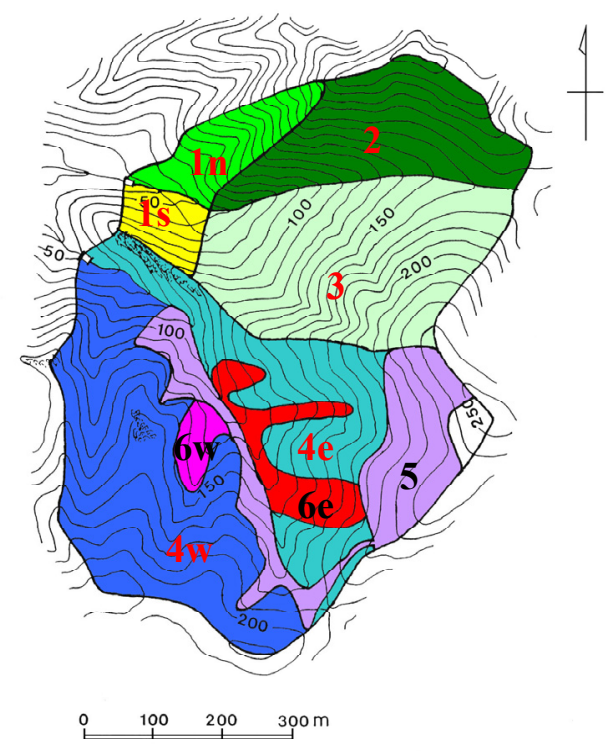

Figure 2: $\quad$ Forest stands in Tatsunokuchi-yama Green Shower Park. 
Table 1: $\quad$ Vegetation in each forest stand.

\begin{tabular}{|c|c|c|c|c|c|c|c|c|}
\hline \multirow{2}{*}{$\begin{array}{c}\text { Color in } \\
\text { above } \\
\text { Figure }\end{array}$} & \multirow{2}{*}{$\begin{array}{l}\text { Forest } \\
\text { Stand ID }\end{array}$} & \multirow{2}{*}{$\begin{array}{l}\text { Forest } \\
\text { Type }\end{array}$} & \multicolumn{2}{|c|}{ Basal Area $\left(\mathrm{m}^{2} \mathrm{ha}^{-1}\right)$} & \multicolumn{2}{|c|}{$\begin{array}{c}\text { Stem Density (number } \\
\mathrm{a}^{-1} \text { ) }\end{array}$} & \multirow{2}{*}{$\begin{array}{c}\text { Maximum } \\
\text { Tree } \\
\text { Height }(m)\end{array}$} & \multirow{2}{*}{$\begin{array}{l}\text { Leaf Area } \\
\text { Index }\left(\mathrm{m}^{2} \mathrm{~m}^{-2}\right)\end{array}$} \\
\hline & & & Evergreen & Deciduous & Evergreen & Deciduous & & \\
\hline & $1 n$ & \multirow{2}{*}{1} & 4.3 & 16.2 & 15.5 & 14.0 & 15.3 & \multirow{2}{*}{5.4} \\
\hline & $1 \mathrm{~s}$ & & 14.7 & 13.8 & 37.0 & 10.0 & 15.3 & \\
\hline & 2 & 2 & 3.3 & 30.2 & 16.0 & 16.5 & 18.5 & 8.6 \\
\hline & 3 & 3 & 7.7 & 24.7 & 14.5 & 11.0 & 15.8 & 8.6 \\
\hline & $4 e$ & \multirow{2}{*}{4} & 2.9 & 16.8 & 13.0 & 15.0 & 13.3 & \multirow{2}{*}{9.4} \\
\hline & $4 w$ & & 20.3 & 21.4 & 40.0 & 28.5 & 17.0 & \\
\hline & 5 & 5 & 19.7 & 0.0 & 13.0 & 0.0 & 11.6 & 3.2 \\
\hline & $6 e$ & \multirow{2}{*}{6} & 4.9 & 5.1 & 12.5 & 7.5 & 9.2 & \multirow{2}{*}{2.9} \\
\hline & $6 w$ & & 3.3 & 20.5 & 18.0 & 18.0 & 13.5 & \\
\hline
\end{tabular}

\section{Methodology}

The solar radiation on the forest floor and surface soil moisture at $5 \mathrm{~cm}$ in depth was scanned every $10 \mathrm{~s}$ and recorded at 10-min intervals in each of nine forest stands, using an solar meter (S-LIB-M003; Onset, USA) and an soil moisture sensor (S-SMA-M003; Onset, USA), respectively. Precipitation above the canopy was measured using a rain gauge at a weather station located at the park base.

Litter moisture $(\theta)$ was simulated in the two drying periods of 14-19 September 2004 in the foliate season and 24 February to 3 March 2005 in the defoliate season. Strictly speaking, the model parameters should differ among the forest stands. However, Tamai and Goto [2] reported that litter moisture depends on the microclimate such as solar radiation, rather than on the intrinsic drying properties of the litter and litter layer. Thus, the same model parameters were used for all forest stands as $a=1.02 \mathrm{E}-04, b=1.3 \mathrm{E}-05, c=1.8$, and $\theta_{\max }=$ 2.0 , as per the values fixed by Tamai [1] in a laboratory experiment.

\section{Results and discussion}

\subsection{Mapping the simulated litter moisture}

Litter moisture $(\theta)$ was simulated every $30 \mathrm{~min}$. The daily minimum litter moisture $\left(\theta_{\min }\right)$ was $2.0 \mathrm{~g} \mathrm{~g}^{-1}$ on the first and last days of the simulated periods because precipitation occurred at this time (Tables 2, 3 and Figs. 3, 4). In contrast, $\theta$ decreased at a different rate in each forest stand among the other simulated days, depending on the level of solar radiation on the forest floor. 
Table 2: Daily minimum litter moisture $\left(\mathrm{g} \mathrm{g}^{-1}\right)$ in the defoliate period (24/Feb.-3/Mar./2005).

\begin{tabular}{|c|c|c|c|c|c|c|c|c|c|}
\hline & Predicted & aily Min & $\mathrm{m}$ Mois & $\left.g^{-1}\right)$ & & & & & \\
\hline date time & $1 n$ & $1 \mathrm{~s}$ & 2 & 3 & $4 \mathrm{e}$ & $4 w$ & 5 & $6 e$ & $6 w$ \\
\hline 24/Feb./2005 & 2.000 & 2.000 & 2.000 & 2.000 & 2.000 & 2.000 & 2.000 & 2.000 & 2.000 \\
\hline 25/Feb./2005 & 1.198 & 1.479 & 0.683 & 0.906 & 1.003 & 1.195 & 0.680 & 1.116 & 0.872 \\
\hline 26/Feb./2005 & 0.783 & 1.148 & 0.352 & 0.526 & 0.635 & 0.759 & 0.354 & 0.716 & 0.377 \\
\hline 27/Feb./2005 & 0.539 & 0.811 & 0.226 & 0.299 & 0.428 & 0.476 & 0.240 & 0.452 & 0.198 \\
\hline 28/Feb./2005 & 0.383 & 0.570 & 0.175 & 0.201 & 0.278 & 0.322 & 0.179 & 0.307 & 0.148 \\
\hline 1/Mar./2005 & 0.286 & 0.429 & 0.145 & 0.160 & 0.207 & 0.245 & 0.151 & 0.216 & 0.134 \\
\hline 2/Mar./2005 & 0.228 & 0.334 & 0.136 & 0.141 & 0.176 & 0.194 & 0.140 & 0.177 & 0.130 \\
\hline 3/Feb./2005 & 2.000 & 2.000 & 2.000 & 2.000 & 2.000 & 2.000 & 2.000 & 2.000 & 2.000 \\
\hline
\end{tabular}

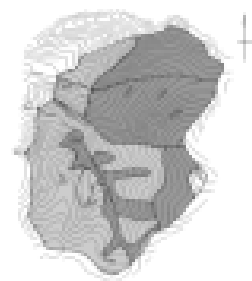

(a) $25 / \mathrm{Feb} . / 2005$

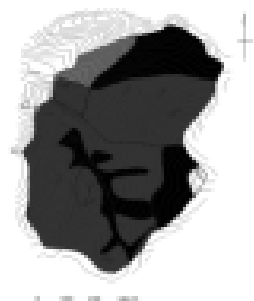

(d) $28 / \mathrm{Feb} . / 2005$

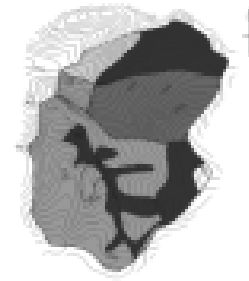

(b) $26 / \mathrm{Feb} . / 2005$

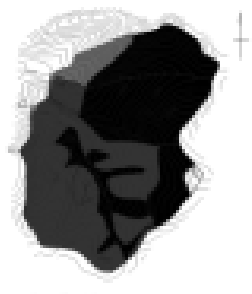

(e) $1 / \mathrm{Mar} / 2005$

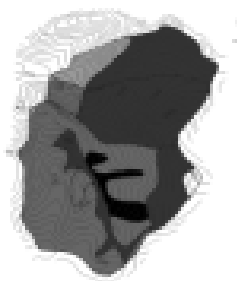

(c) $27 / \mathrm{Feb} . / 2005$

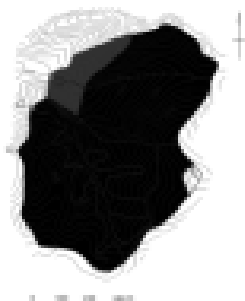

(f) 2 /Mar./2005

\begin{tabular}{|c|c|}
\hline $\begin{array}{c}\text { Litter } \\
\text { Moisture } \\
\left(\mathrm{g} \mathrm{g}^{-1}\right)\end{array}$ & $\begin{array}{c}\text { Color in } \\
\text { Maps }\end{array}$ \\
\hline $1.00-$ & \\
\hline $0.60-1.00$ & \\
\hline $0.40-0.60$ & \\
\hline $0.20-0.40$ & \\
\hline-0.20 & \\
\hline
\end{tabular}

Figure 3: Litter dry speed in each forest stand in the defoliate period (25/Feb.-2/Mar./2005).

In the defoliate period, $\theta$ was $<0.2 \mathrm{~g} \mathrm{~g}^{-1}$ and the fire risk was judged to be highest in seven of nine forest stands on 2 May. In contrast, the spatial variation in $\theta$ was greatest at $0.198-0.811 \mathrm{~g} \mathrm{~g}^{-1}$ on 27 February. This means that the rate of litter drying and fire risk differ among forest stands. Thus, it is significant to construct forest fire warning systems for each forest stand to manage people's activities to prevent forest fire. 
402 Modelling, Monitoring and Management of Forest Fires I

Table 3: Daily minimum litter moisture $\left(\mathrm{g} \mathrm{g}^{-1}\right)$ in the foliate period (1419/Sep./2004).

\begin{tabular}{|c|c|c|c|c|c|c|c|c|c|}
\hline & \multicolumn{4}{|c|}{ Predicted Daily Minmam Moist. $\left(\mathrm{g} \mathrm{g}^{-1}\right)$} & \multirow[b]{2}{*}{$4 \mathrm{e}$} & \multirow[b]{2}{*}{$4 w$} & \multirow[b]{2}{*}{5} & \multirow[b]{2}{*}{$6 e$} & \multirow[b]{2}{*}{$6 w$} \\
\hline date time & $1 \mathrm{n}$ & $1 \mathrm{~s}$ & 2 & 3 & & & & & \\
\hline 14/Sep./2004 & 2.000 & 2.000 & 2.000 & 2.000 & 2.000 & 2.000 & 2.000 & 2.000 & 2.000 \\
\hline 15/Sep./2004 & 1.498 & 1.798 & 1.054 & 1.474 & 1.550 & 1.767 & 1.789 & 1.468 & 1.828 \\
\hline $16 /$ Sep./2004 & 1.233 & 1.627 & 0.652 & 1.117 & 1.205 & 1.577 & 1.626 & 1.154 & 1.651 \\
\hline 17/Sep./2004 & 1.084 & 1.508 & 0.520 & 0.921 & 1.096 & 1.445 & 1.519 & 1.023 & 1.517 \\
\hline 18/Sep./2004 & 0.929 & 1.375 & 0.373 & 0.742 & 0.926 & 1.324 & 1.395 & 0.823 & 1.385 \\
\hline 19/Sep./2004 & 2.000 & 2.000 & 2.000 & 2.000 & 2.000 & 2.000 & 2.000 & 2.000 & 2.000 \\
\hline
\end{tabular}

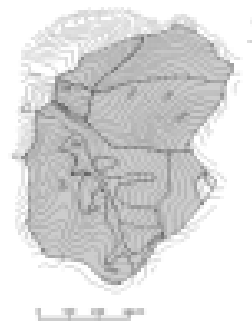

(a) $15 /$ Sep./2004

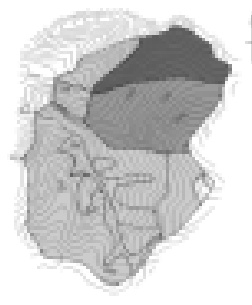

(c) $17 /$ Sep./2004

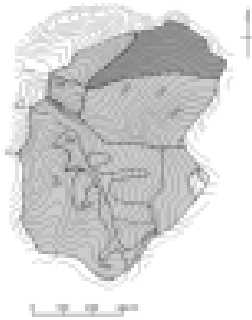

(b) $16 / \mathrm{Sep} . / 2004$

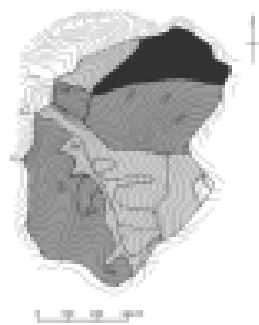

(d) $18 / \mathrm{Sep} . / 2004$

\begin{tabular}{|c|c|}
\hline $\begin{array}{c}\text { Litter } \\
\text { Moisture } \\
\left(\mathrm{g} \mathrm{g}^{-1}\right)\end{array}$ & $\begin{array}{c}\text { Color in } \\
\text { Maps }\end{array}$ \\
\hline $1.00-$ & \\
\hline $0.60-1.00$ & \\
\hline $0.40-0.60$ & \\
\hline $0.20-0.40$ & \\
\hline-0.20 & \\
\hline
\end{tabular}

Figure 4: Litter dry speed in each forest stand in the foliate period (1518/Sep./2004). 
In the foliate period, the rate of litter drying was slower than in the defoliate period. This was caused by the low solar radiation on the forest floor. However, $\theta_{\text {min }}$ decreased to $0.373 \mathrm{~g} \mathrm{~g}^{-1}$ in stand 2 on 18 September.

\subsection{Simulated litter moisture and observed surface soil moisture}

The comparison of the simulated litter moisture and observed surface soil moisture (Fig. 5a) indicates that the rates of litter drying corresponded well. This suggests the possibility of monitoring litter moisture using surface soil moisture measurements. However, for stand 3 in the defoliate period, the simulated and observed rates of litter drying did not correspond well (Fig. 5b). The surface soil moisture was measured as constant during night after 27 September. This suggests that solar radiation on the forest floor has a great effect on the surface soil and litter moisture.
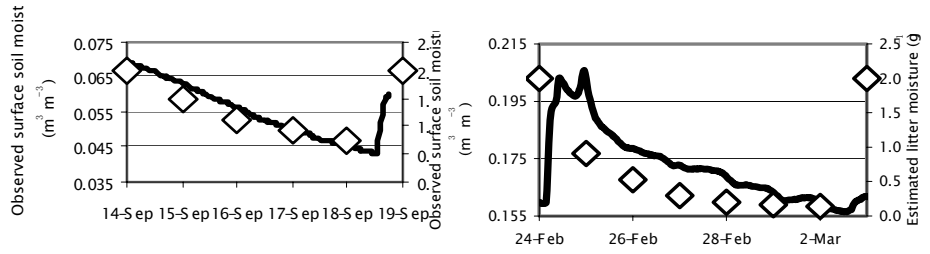

(a) The case in Plot 3 in the foliate period. (b) The case in Plot 3 in the defoliate period.

Figure 5: The comparison between observed surface soil moisture (solid line) and estimated litter moisture (white point).

\section{Conclusion}

The litter moisture content ratio were predicted with the model using meteorological data and forest fire hazard were estimated in Tatsunokuchi-yama Green Shower Park, Japan with around 40ha forested area for 2 litter drying periods as a trial. Litter moisture was simulated every $30 \mathrm{~min}$. In defoliate period, litter moisture was decreased at a different rate in each forest stand among the other simulated days, depending on the level of solar radiation on the forest floor.

This means that the rate of litter drying and fire risk differ among forest stands. Thus, it is significant to construct forest fire warning systems for each forest stand to manage people's activities to prevent forest fire. In the foliate period, the rate of litter drying was slower than in the defoliate period. These results suggest that the predicted model for litter moisture and fire risk mapping can be used to manage people's activities in this public forested area.

The simulated litter moisture and observed surface soil moisture corresponded well. This suggests the possibility of monitoring litter moisture using surface soil moisture measurements. 
404 Modelling, Monitoring and Management of Forest Fires I

\section{References}

[1] Tamai, K., Estimation model for litter moisture content ratio on forest floor. IAHS Publ., 270, pp.53-57, 2001.

[2] Tamai, K. \& Goto, Y., Fuel moisture estimation model for deciduous secondary forest in Japan -A comparison of parameters under different canopies-. Proceedings of 5th Symposium on fire and forest meteorology (AMS), P5.7., 2003. 